\title{
Blood pressure
}

National Diabetes Information Clearinghouse (NDIC)

\section{Definitions}

Artery

Defined by National Diabetes Information Clearinghouse (NDIC)

Blood vessels

Defined by National Diabetes Information Clearinghouse (NDIC)

Source

National Diabetes Information Clearinghouse (U.S.). (2009). The diabetes dictionary. [Bethesda, Md.]: U.S. Dept. of Health and Human Services, National Institutes of Health, National Institute of Diabetes and Digestive and Kidney Diseases, National Diabetes Information Clearinghouse.

The force of blood exerted on the inside walls of blood vessels. Blood pressure is expressed as two numbers. For example, a blood pressure result of $120 / 80$ is said as "120 over 80 ." The first number is the systolic pressure, or the pressure when the heart pushes blood into the arteries. The second number is the diastolic pressure, or the pressure when the heart rests. 